\title{
In Vitro Susceptibility of Canine Influenza A (H3N8) Virus to Nitazoxanide and Tizoxanide
}

\author{
Laura V. Ashton, Robert L. Callan, Sangeeta Rao, and Gabriele A. Landolt \\ Department of Clinical Sciences, College of Veterinary Medicine and Biomedical Sciences, Colorado State University, \\ 300 West Drake Road, Fort Collins, CO 80523, USA \\ Correspondence should be addressed to Gabriele A. Landolt, landoltg@colostate.edu
}

Received 7 May 2010; Accepted 15 July 2010

Academic Editor: Maurice Pensaert

Copyright ( $) 2010$ Laura V. Ashton et al. This is an open access article distributed under the Creative Commons Attribution License, which permits unrestricted use, distribution, and reproduction in any medium, provided the original work is properly cited.

\begin{abstract}
Infection of dogs with canine influenza virus (CIV) is considered widespread throughout the United States following the first isolation of CIV in 2004. While vaccination against influenza A infection is a common and important practice for disease control, antiviral therapy can serve as a valuable adjunct in controlling the impact of the disease. In this study, we examined the antiviral activity of nitazoxanide (NTZ) and tizoxanide (TIZ) against three CIV isolates in vitro. NTZ and TIZ inhibited virus replication of all CIVs with $50 \%$ and $90 \%$ inhibitory concentrations ranging from 0.17 to $0.21 \mu \mathrm{M}$ and from 0.60 to $0.76 \mu \mathrm{M}$, respectively. These results suggest that NTZ and TIZ are effective against CIV and may be useful for treatment of canine influenza in dogs but further investigation of the in vivo efficacy against CIV as well as the drug's potential for toxicity in dogs is needed.
\end{abstract}

\section{Introduction}

In 2004, canine influenza virus (CIV) was first isolated from the lung tissue of a racing greyhound dog that had died of pneumonia [1]. Since its first isolation, the virus has spread into the nongreyhound dog population and has caused outbreaks of respiratory disease in dogs throughout the United States [1-3]. As the virus is transmitted in aerosols created by coughing and sneezing, close contact and closed environments favor virus spread. Thus, the highest incidence of infection is found in dogs that are housed in groups, such as at humane shelters $[2,3]$. While most dogs infected with CIV have generally mild illness, a small percentage of dogs develop a more severe form of disease characterized by persistent fever, lethargy, dyspnea, and clinical signs of bronchopneumonia [3]. Vaccination is an important practice for the control of influenza infection in many species. Despite the fact that a conditionally licensed, inactivated CIV vaccine has recently become available for use in the United States (Canine Influenza Vaccine, Intervet/Schering-Plough Animal Health, Summit, NJ), it is currently unknown how effective vaccination will be in preventing disease in dogs. Moreover, as effective immunoprotection through active immunization typically requires the administration of several doses of the target antigen (priming and booster doses), vaccination may not represent a realistic approach to confer protection to the transient canine populations housed at humane shelters.

In contrast, antiviral therapy could represent a viable option for the immediate protection of dogs during canine influenza outbreaks, as antiviral drugs do not rely on the induction of a protective immune response [4]. Antiviral agents also represent a potential influenza virus-specific treatment option. A number of animal shelters have employed oseltamivir phosphate (TamiFlu, Roche, Basel, Switzerland) for treatment of dogs during CIV outbreaks. Despite this, the use of oseltamivir phosphate in dogs is not recommended as the dose, duration of treatment, safety, as well as the efficacy of this drug against CIV isolates are unknown [3]. More importantly, oseltamivir should be reserved as a vital defense for the protection of human health during an influenza pandemic. Several studies have demonstrated that the use of antiviral drugs can result in the development of antiviral resistance among influenza A viruses. Indiscriminate use of oseltamivir could potentially reduce 
the effectiveness of treatment during an influenza pandemic [5-8].

Nitazoxanide (NTZ), a thiazolide compound, has been shown to have antimicrobial activity against a variety of parasites, anaerobic bacteria, and viruses [9-13]. The drug is labeled for treatment of infectious enteritis caused by Giardia lamblia and Cryptosporidium parvum in humans and for the treatment of equine protozoal myeloencephalitis (EPM) in horses. NTZ has moderate oral bioavailability and, once absorbed, the compound is hydrolyzed in plasma to form the active metabolite tizoxanide (TIZ). NTZ is generally well tolerated and the most commonly reported side effects include mild abdominal pain, nausea, and diarrhea. The compound has been found effective for the treatment of rotavirus and norovirus gastroenteritis in human clinical trials $[14,15]$. While the mechanism for its broad-spectrum antiviral activity is not fully understood, it is most likely mediated by a cell-specific rather than a virus-specific effect. This notion is supported by findings of a recent study that demonstrated that NTZ inhibited replication of several human- and avian-lineage influenza $\mathrm{A}$ viruses in vitro possibly by blocking trafficking of the viral hemagglutinin (HA) protein between the endoplasmic reticulum and the Golgi complex [16]. Taken together, these data suggest that NTZ may be a valuable treatment for dogs infected with CIV, provided that the drug also has inhibitory activity against canine influenza viruses. In this report, we present results of in vitro studies characterizing the activities of NTZ and TIZ against three recent canine influenza virus isolates.

\section{Materials and Methods}

2.1. Influenza Viruses. Field isolates of A/Canine/Colorado1/224986/06 (Ca/CO-1), A/Canine/Colorado-3/3/06 (Ca/ CO-3), and A/Canine/Colorado-4/2025974/07 (Ca/CO-4) (all H3N8) were cultivated in Madin-Darby canine kidney (MDCK) cells as previously described in [17]. To confirm sequence identity, the full-length protein coding regions of the $\mathrm{HA}$ and neuraminidase (NA) genes of $\mathrm{Ca} / \mathrm{CO}-1, \mathrm{Ca} / \mathrm{CO}$ 3 , and $\mathrm{Ca} / \mathrm{CO}-4$ were amplified by RT-PCR and sequenced as previously described in [18].

2.2. Determination of Cell Toxicity. Nitazoxanide (NTZ) was provided by IDEXX Laboratories (Westbrook, ME, USA) and tizoxanide (TIZ) was provided by Romark Laboratories (Tampa, FL, USA). Stock solutions were prepared by dissolving $50 \mathrm{mg}$ NTZ or TIZ in $1 \mathrm{~mL}$ of dimethyl sulfoxide (DMSO), divided into aliquots, and stored at $-80^{\circ} \mathrm{C}$. Working solutions of NTZ and TIZ were prepared fresh by diluting the stock solution to the appropriate $\mu \mathrm{M}$ concentration in MEM supplemented with $100 \mathrm{IU}$ penicillin/streptomycin, $100 \mathrm{mM}$ L-glutamine, $0.5 \%$ bovine serum albumin (GIBCO, Carlsbad, CA, USA) and $1 \mu \mathrm{g} / \mathrm{mL}$ tolylsulfoyl phenylalanyl choromthyl ketone-(TPCK-) treated trypsin (Worthington Biochemical Corporation, Lakewood, NJ, USA). Working solutions of NTZ or TIZ were then added to a confluent monolayer of MDCK cells in 96-well tissue culture plates (BD Biosciences, San Jose, CA, USA). Negative (no NTZ or TIZ) and DMSO (1\%) control samples were included in each experiment. Plates were then incubated at $37^{\circ} \mathrm{C}$ with $5 \%$ $\mathrm{CO}_{2}$. Cell cytotoxicity of NTZ and TIZ was determined after 96 hours using the alamar blue reduction assay by methods previously described [19]. Cell viability was expressed as the $\mathrm{CC}_{50}$, which is the Cytotoxic Concentration at which a $50 \%$ decrease in alamar blue reduction was noted when compared to the negative control.

2.3. Determination of NTZ and TIZ Inhibitory Concentrations. Confluent monolayers of MDCK cells cultured in 96well tissue culture plates were infected at a multiplicity of infection (MOI) of 0.001 with $\mathrm{Ca} / \mathrm{CO}-1, \mathrm{Ca} / \mathrm{CO}-3$, or $\mathrm{Ca} / \mathrm{CO}-4$. Infected plates were incubated with agitation for 2 hours at $37^{\circ} \mathrm{C}$ with $5 \% \mathrm{CO}_{2}$. After incubation, the virus inoculum was removed and $200 \mu \mathrm{L}$ of working solutions of NTZ or TIZ, at concentrations ranging from $0.001 \mu \mathrm{M}$ to $4.0 \mu \mathrm{M}$, were added to each well. Positive (no NTZ or TIZ) and negative (no virus) control samples as well as a $1 \%$ DMSO control were included in each experiment. Plates were then incubated at $37^{\circ} \mathrm{C}$ with $5 \% \mathrm{CO}_{2}$ for 72 hours. The virus titer in cell culture supernatants of each well, expressed as tissue culture infective dose (TCID) $)_{50}$ per $\mathrm{mL}$, was calculated using the method of Reed and Muench as previously described [17].

2.4. Statistical Analysis. Each experiment was done on 3 different occasions with 8 samples of each NTZ or TIZ concentration per replicate $(n=24)$. The amount of infectious CIV in the treated culture supernatant was expressed as a percentage of the control value and was calculated by dividing the titer of each treated sample by the average of the untreated positive control. To normalize the data, the percentage control values were log transformed. The data was analyzed by polynomial regression analysis. Based on the fit and overall variance $\left(R^{2}\right)$, the best model was selected to determine the antiviral effective concentrations that result in the $50 \%\left(\mathrm{EC}_{50}\right)$ and $90 \%\left(\mathrm{EC}_{90}\right)$ reduction of virus titers in the culture supernatants. Selectivity index (SI) was calculated by dividing the $\mathrm{CC}_{50}$ by the $\mathrm{EC}_{50}$. To evaluate the association between the independent variables (dose, drug, and strain) and the outcome variable (viral titer relative to the control), the data was analyzed a multivariable linear regression analysis with a mixed model approach PROC MIXED (SAS v9.1, SAS Institute Incorporated, Cary, NC) by specifying the fixed and random effects. A critical alpha for all statistical analyses was set $a$ priori at 0.05 .

\section{Results}

Sequencing and phylogenetic analyses of the HA and NA genes of the three canine influenza isolates used in this study confirmed that $\mathrm{Ca} / \mathrm{CO}-1, \mathrm{Ca} / \mathrm{CO}-3$, and $\mathrm{Ca} / \mathrm{CO}-4$ clustered with the contemporary canine $\mathrm{H} 3 \mathrm{~N} 8$ influenza viruses, placing them into the previously described distinct canine sublineages of the equine H3 "Florida lineage" (Figure 1) [2]. NTZ and its active metabolite TIZ exhibited dosedependent inhibition of extracellular virus production by 


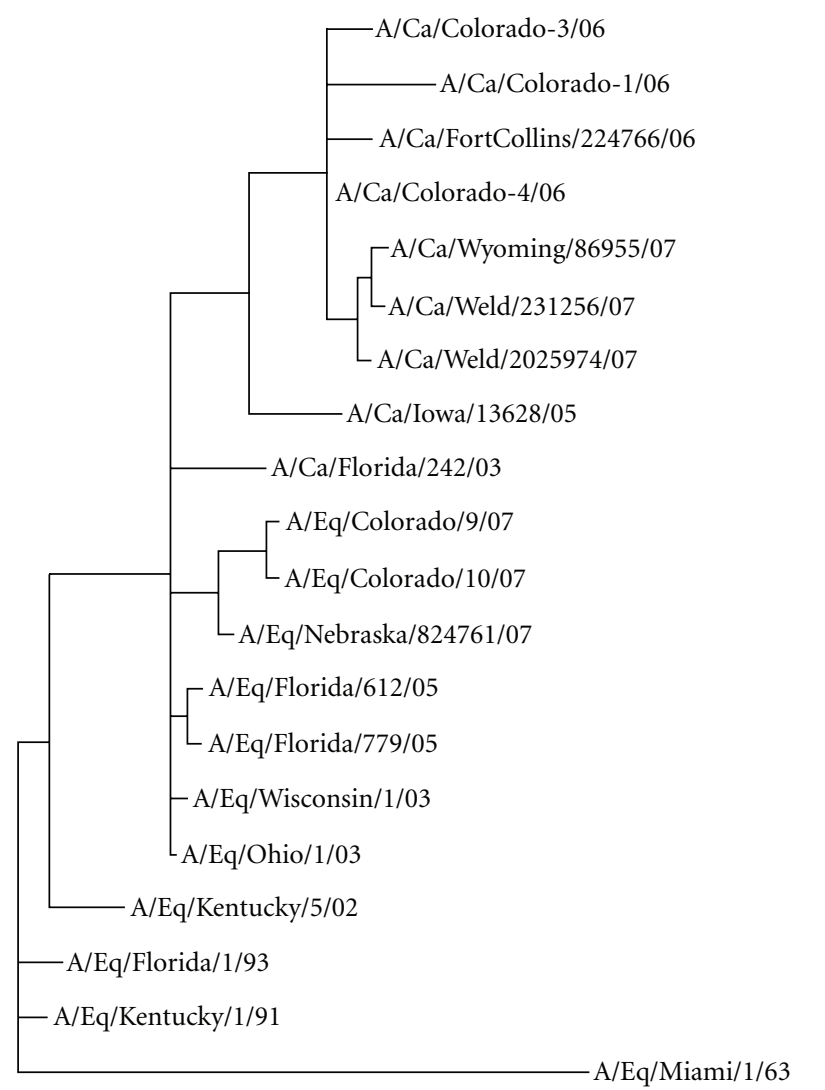

- 5 changes

Figure 1: Phylogenetic relationships at the nucleotide level among the hemagglutinin 3 (H3) genes of contemporary canine (including $\mathrm{Ca} / \mathrm{CO}-1, \mathrm{Ca} / \mathrm{CO}-3$, and $\mathrm{Ca} / \mathrm{CO}-4$ used in this study) and equine influenza viruses. Scale bar represents a difference at the nucleotide level of $5 \%$.

MDCK cells. Complete inhibition of in vitro replication of $\mathrm{Ca} / \mathrm{CO}-1, \mathrm{Ca} / \mathrm{CO}-3$, and $\mathrm{Ca} / \mathrm{CO}-4$ in MDCK cells in the presence of NTZ or TIZ was observed at a concentration of $5 \mu \mathrm{M}$. At concentrations of NTZ or TIZ between 1 and $2 \mu \mathrm{M}$, replication of all three CIV isolates was partially inhibited resulting in the reduction of virus titers by $3 \log _{10}$ compared to the control wells.

To determine $\mathrm{EC}_{50}$ and $\mathrm{EC}_{90}$, assays were performed using NTZ or TIZ concentrations ranging from 0.001 to $2 \mu \mathrm{M}$. Dose response curves for $\mathrm{Ca} / \mathrm{CO}-1, \mathrm{Ca} / \mathrm{CO}-3$, and $\mathrm{Ca} / \mathrm{CO}-4$ viral titers are shown in Figure 2 . The best model selected with good fit and $82 \%$ overall variance $\left(R^{2}\right)$ was the Quadratic polynomial model. The multivariable linear regression analysis, the selected model for the viral titers with CIV strain $\mathrm{Ca} / \mathrm{CO}-4$ was significantly higher $(P<.05)$ than $\mathrm{Ca} / \mathrm{CO}-1$. The viral titers with $\mathrm{CIV}$ strain $\mathrm{Ca} / \mathrm{CO}-4$ were lower than $\mathrm{Ca} / \mathrm{CO}-1$ and $\mathrm{Ca} / \mathrm{CO}-3$ with $P=.07$. However, this did not result in significant differences between the $\mathrm{EC}_{50}$ and $\mathrm{EC}_{90}$ for the three viral isolates (Table 1). The model also indicated that the viral titers with addition of TIZ were significantly higher $(P<.05)$ compared to those

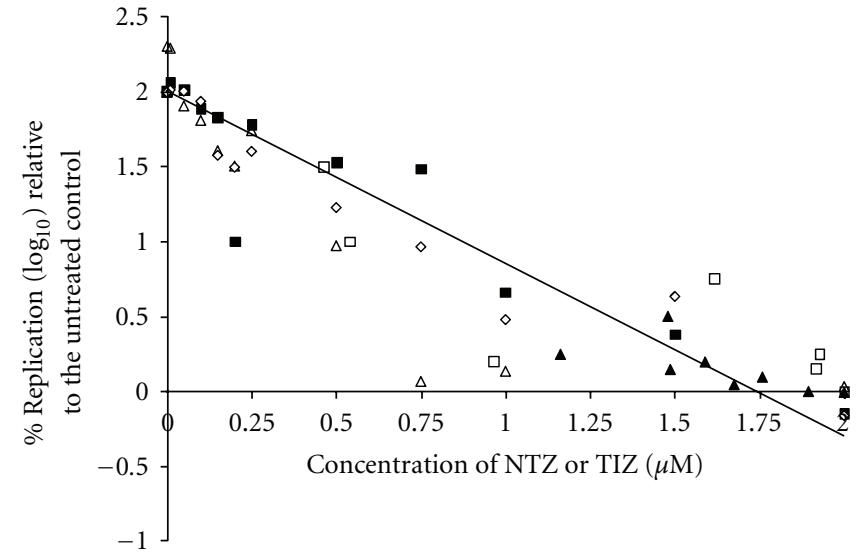

FIgURE 2: Effect of NTZ (closed) or TIZ (open) against CIV $(\mathrm{Ca} / \mathrm{CO}-1(\boldsymbol{\Delta}, \Delta) \mathrm{Ca} / \mathrm{CO}-3(\boldsymbol{\square}, \square)$ and $\mathrm{Ca} / \mathrm{CO}-4(\diamond, \diamond))$ relative to the replication of the untreated controls in MDCK cells.

with addition of NTZ. While the $\mathrm{EC}_{50}$ values for NTZ and TIZ for the three CIV isolates $(0.17-0.21 \mu \mathrm{M})$ were similar for each strain (Table 1 ), the $\mathrm{EC}_{90}$ values were consistently 3.5 times higher than the $\mathrm{EC}_{50}(0.60-0.76 \mu \mathrm{M})$ regardless of strain or drug form (NTZ or TIZ). In contrast, the selectivity index of TIZ against all three CIV strains was double the value obtained for the parent compound NTZ (Table 1). This was directly related to the $\mathrm{CC}_{50}$ values for NTZ and TIZ on MDCK cells, which were $64.9 \mu \mathrm{M}$ and $130 \mu \mathrm{M}$, respectively.

\section{Discussion}

The recent emergence of canine influenza virus represents a serious threat to canine health and welfare. As dogs possess no natural immunity against this virus, all dogs, regardless of age, breed, or sex are potentially susceptible to infection. While the total number of CIV infections that have occurred since the appearance of the virus in 2004 is unknown, a recent one-year study performed by our laboratory found CIV PCR-positive dogs in 11 of 16 (69\%) Colorado humane shelters that experienced outbreaks of canine respiratory disease [20]. These results support the importance of CIV as a cause of morbidity in shelter dogs in the United States. Despite the fact that an inactivated vaccine has recently become available, antiviral therapy may be beneficial in fluctuating populations such as in shelters because initial vaccination series for the canine vaccine should include two doses. In this study, we report that the thiazolide NTZ and its active metabolite TIZ possess potent antiviral activities against three genetically distinct canine influenza viruses. Inhibition of virus replication was dose dependent and the concentrations of NTZ and TIZ needed to inhibit CIV replication were comparable to the concentrations found to be effective against Hepatitis $\mathrm{B}$ Virus and Hepatitis C Virus (HCV) $(0.12-0.21 \mu \mathrm{M})$ [21] but lower than the concentrations needed to inhibit several human influenza viruses and an avian isolate $(1.63-3.25 \mu \mathrm{M})$ [16]. Several studies indicate that concentrations necessary 
TABLE 1: In vitro activity of nitazoxanide (NTZ) and its active metabolite tizoxanide (TIZ) on clinical isolates of canine influenza virus (CIV).

\begin{tabular}{lcccc}
\hline Virus & Drug & EC $_{50}$ & EC $_{90}$ & SI \\
\hline \multirow{2}{*}{$\mathrm{Ca} / \mathrm{CO}-1$} & NTZ & $0.20 \pm 0.01$ & $0.70 \pm 0.03$ & 331 \\
& TIZ & $0.20 \pm 0.01$ & $0.72 \pm 0.03$ & 644 \\
\hline \multirow{2}{*}{$\mathrm{Ca} / \mathrm{CO}-3$} & NTZ & $0.17 \pm 0.01$ & $0.60 \pm 0.03$ & 391 \\
& TIZ & $0.17 \pm 0.01$ & $0.62 \pm 0.03$ & 751 \\
\hline \multirow{2}{*}{$\mathrm{Ca} / \mathrm{Co}-4$} & NTZ & $0.20 \pm 0.01$ & $0.71 \pm 0.03$ & 329 \\
& TIZ & $0.19 \pm 0.01$ & $0.70 \pm 0.03$ & 374 \\
$\mathrm{CIV}$ & NTZ & $0.21 \pm 0.02$ & $0.76 \pm 0.03$ & $0.75 \pm 0.03$ \\
& TIZ & $0.21 \pm 0.02$ & 309 \\
\hline
\end{tabular}

$\mathrm{EC}_{50}$ or 90 : Concentration $(\mu \mathrm{M})$ of NTZ or TIZ at which a 2 -fold $(50 \%)$ or 10 -fold $(90 \%)$ reduction of viral titer is relative to untreated controls. $\mathrm{EC}_{50}$ and $\mathrm{EC}_{90}$ are expressed as means \pm standard deviation.

SI: Selectivity Index $\left(\mathrm{CC}_{50} / \mathrm{EC}_{50}\right)$.

Viral titers of three CIV isolates were analyzed using polynomial regression analysis. 95\% confidence intervals for each value are displayed in parenthesis.

to inhibit CIV replication are readily achievable in plasma following oral administration of NTZ to humans [22, 23]. In humans, the drug is typically well tolerated and only mild, and generally transient, adverse effects have been reported $[23,24]$. In contrast, since the drug is also active against microaerophilic and anaerobic bacteria that are a part of the normal gastrointestinal flora, substantial side effects, such as enterocolitis, have been described in horses following administration of NTZ [25]. Since cytotoxic levels observed in vitro do not necessarily indicate the actual toxicity of NTZ in the animal, further research is needed to determine the pharmacokinetics and safety of NTZ in dogs.

Currently, two classes of antiviral agents are available for prophylaxis and treatment of influenza A virus infections; the M2 ion channel blockers and the neuraminidase inhibitors. The M2 ion channel blockers amantadine and rimantadine inhibit virus replication through allosteric inhibition of the M2 protein, thus blocking the flow of $\mathrm{H}^{+}$ions from the acidified endosomal compartment into the interior of the virion. The neuraminidase inhibitors, oseltamivir phosphate, and zanamivir block the active site of the viral neuraminidase protein preventing the release of the influenza virion from infected cells. Of these antivirals, oseltamivir phosphate is currently considered the drug of choice for treatment of influenza in humans. However, as resistance to oseltamivir and the $\mathrm{M} 2$ ion channel blockers can be conferred by a single point mutation [26-28], antiviral resistance among influenza A isolates is rapidly increasing [6,29-31]. As the viral RNA polymerase lacks proofreading function, influenza A viruses demonstrate high mutations rates. Given the plasticity of the influenza virus genome, selective pressures will inevitably lead to mutational changes.

Unlike direct-acting antiviral drugs, NTZ does not inhibit viral RNA transcription or block viral protein synthesis, instead, the drug interferes with cellular posttranscriptional protein processing and may interfere with the assembly of viral glycoproteins, preventing the formation of mature viral particles $[9,21]$. For example, NTZ has been shown to inhibit the function of protein disulfide isomerase [32], an important enzyme for three-dimensional protein formation in the endoplasmic reticulum (ER). More specifically, Rossignol and colleagues demonstrated that
NTZ exerts its anti-influenza effects by interfering with the maturation and the intracellular trafficking of the HA protein [16]. Given the drug's activity against a wide range of viral pathogens, it has been speculated that NTZ's antiviral effect is mediated by a cell-specific rather than a virusspecific mechanism [16]. This hypothesis is supported by the finding that transfection of HCV viral RNA isolated from NTZ or TIZ-resistant replicon-containing cell lines did not transfer NTZ or TIZ resistance, suggesting an absence of acquired resistance in the HCV genome [33]. Taken together, this suggests that the potential for the development of antiviral resistance to NTZ by mutational adaptation of the virus genome may be minimal.

\section{Conclusions}

Our results represent the first report of the in vitro activity of NTZ and its active metabolite TIZ against three genetically distinct, contemporary canine influenza viruses. The use of a broad-spectrum antiviral such as NTZ in conjunction with supportive care may reduce the morbidity and risk of secondary complications associated with canine influenza. The use of NTZ as a prophylactic and therapeutic antiviral during CIV outbreaks could possibly shorten the duration of nasal virus shedding, thus limiting the spread of the virus. However, further investigation of the in vivo efficacy against CIV as well as the drug's potential for toxicity in dogs is needed.

\section{Acknowledgment}

This research was sponsored by IDEXX Laboratories (Westbrook, ME) and Romark Laboratories (Tampa, FL, USA).

\section{References}

[1] P. C. Crawford, E. J. Dubovi, W. L. Castleman et al., "Transmission of equine influenza virus to dogs," Science, vol. 310, no. 5747, pp. 482-485, 2005.

[2] S. Payungporn, P. C. Crawford, T. S. Kouo et al., "Influenza A virus (H3N8) in dogs with respiratory disease, Florida," Emerging Infectious Diseases, vol. 14, no. 6, pp. 902-908, 2008. 
[3] E. J. Dubovi and B. L. Njaa, "Canine Influenza," Veterinary Clinics of North America-Small Animal Practice, vol. 38, no. 4, pp. 827-835, 2008.

[4] C. Buonavoglia and V. Martella, "Canine respiratory viruses," Veterinary Research, vol. 38, no. 2, pp. 355-373, 2007.

[5] P. K. C. Cheng, T. W. C. Leung, E. C. M. Ho et al., "Oseltamivir-and amantadine-resistant influenza viruses A (H1N1)," Emerging Infectious Diseases, vol. 15, no. 6, pp. 966968, 2009.

[6] N. J. Dharan, L. V. Gubareva, J. J. Meyer et al., "Infections with oseltamivir-resistant influenza $\mathrm{A}(\mathrm{H} 1 \mathrm{~N} 1)$ virus in the united states," Journal of the American Medical Association, vol. 301, no. 10, pp. 1034-1041, 2009.

[7] M. Lipsitch, T. Cohen, M. Murray, and B. R. Levin, "Antiviral resistance and the control of pandemic influenza," PLoS Medicine, vol. 4, no. 1, article e15, 2007.

[8] A. Patel and S. E. Gorman, "Stockpiling antiviral drugs for the next influenza pandemic," Clinical Pharmacology and Therapeutics, vol. 86, no. 3, pp. 241-243, 2009.

[9] J.-F. Rossignol, “Thiazolides: a new class of antiviral drugs," Expert Opinion on Drug Metabolism \& Toxicology, vol. 5, no. 6, pp. 667-674, 2009.

[10] E. B. Keeffe and J.-F. Rossignol, "Treatment of chronic viral hepatitis with nitazoxanide and second generation thiazolides," World Journal of Gastroenterology, vol. 15, no. 15, pp. 1805-1808, 2009.

[11] G. Gargala, L. Le Goff, J. J. Ballet, L. Favennec, A. V. Stachulski, and J. F. Rossignol, "In vitro efficacy of nitro- and halogenothiazolide/thiadiazolide derivatives against Sarcocystis neurona," Veterinary Parasitology, vol. 162, no. 3-4, pp. 230-235, 2009.

[12] G. A. Pankuch and P. C. Appelbaum, "Activities of tizoxanide and nitazoxanide compared to those of five other thiazolides and three other agents against anaerobic species," Antimicrobial Agents \& Chemotherapy, vol. 50, no. 3, pp. 1112-1117, 2006.

[13] J. Müller, G. Rühle, N. Müller, J.-F. Rossignol, and A. Hemphill, "In vitro effects of thiazolides on Giardia lamblia WB clone C6 cultured axenically and in coculture with Caco2 cells," Antimicrobial Agents \& Chemotherapy, vol. 50, no. 1, pp. 162-170, 2006.

[14] J.-F. Rossignol and Y. M. El-Gohary, "Nitazoxanide in the treatment of viral gastroenteritis: a randomized double-blind placebo-controlled clinical trial," Alimentary Pharmacology \& Therapeutics, vol. 24, no. 10, pp. 1423-1430, 2006.

[15] J.-F. Rossignol, M. Abu-Zekry, A. Hussein, and M. G. Santoro, "Effect of nitazoxanide for treatment of severe rotavirus diarrhoea: randomised double-blind placebo-controlled trial," The Lancet, vol. 368, no. 9530, pp. 124-129, 2006.

[16] J. F. Rossignol, S. La Frazia, L. Chiappa, A. Ciucci, and M. G. Santoro, "Thiazolides, a new class of anti-influenza molecules targeting viral hemagglutinin at the post-translational level," Journal of Biological Chemistry, vol. 284, no. 43, pp. 2979829808, 2009.

[17] G. A. Landolt, A. I. Karasin, L. Phillips, and C. W. Olsen, "Comparison of the pathogenesis of two genetically different H3N2 influenza a viruses in pigs," Journal of Clinical Microbiology, vol. 41, no. 5, pp. 1936-1941, 2003.

[18] A. I. Karasin, I. H. Brown, S. Carman, and C. W. Olsen, "Isolation and characterization of H4N6 avian influenza viruses from pigs with pneumonia in Canada," Journal of Virology, vol. 74, no. 19, pp. 9322-9327, 2000.

[19] J. O'Brien, I. Wilson, T. Orton, and F. Pognan, "Investigation of the Alamar Blue (resazurin) fluorescent dye for the assessment of mammalian cell cytotoxicity," European Journal of Biochemistry, vol. 267, no. 17, pp. 5421-5426, 2000.

[20] M. E. Spindel, S. Dillion, K. F. Lunn et al., "Detection and quantification of canine influenza virus by one-step realtime reverse transcription PCR," Journal of Veterinary Internal Medicine, vol. 21, no. 3, p. 576, 2007.

[21] B. E. Korba, A. B. Montero, K. Farrar et al., "Nitazoxanide, tizoxanide and other thiazolides are potent inhibitors of hepatitis B virus and hepatitis C virus replication," Antiviral Research, vol. 77, no. 1, pp. 56-63, 2008.

[22] J. Broekhuysen, A. Stockis, R. L. Lins, J. De Graeve, and J. F. Rossignol, "Nitazoxanide: pharmacokinetics and metabolism in man," International Journal of Clinical Pharmacology \& Therapeutics, vol. 38, no. 8, pp. 387-394, 2000.

[23] A. Stockis, A.-M. Allemon, S. De Bruyn, and C. Gengler, "Nitazoxanide pharmacokinetics and tolerability in man using single ascending oral doses," International Journal of Clinical Pharmacology \& Therapeutics, vol. 40, no. 5, pp. 213-220, 2002.

[24] A. Stockis, X. Deroubaix, R. Lins, B. Jeanbaptiste, P. Calderon, and J. F. Rossignol, "Pharmacokinetics of nitazoxanide after single oral dose administration in 6 healthy volunteers," International Journal of Clinical Pharmacology \& Therapeutics, vol. 34, no. 8, pp. 349-351, 1996.

[25] M. Esposito, S. Moores, A. Naguleswaran, J. Müller, and A. Hemphill, "Induction of tachyzoite egress from cells infected with the protozoan Neospora caninum by nitro- and bromothiazolides, a class of broad-spectrum anti-parasitic drugs," International Journal for Parasitology, vol. 37, no. 10, pp. 1143$1152,2007$.

[26] Y. Abed, M. Baz, and G. Boivin, "A novel neuraminidase deletion mutation conferring resistance to oseltamivir in clinical influenza A/H3N2 virus," Journal of Infectious Diseases, vol. 199, no. 2, pp. 180-183, 2009.

[27] M. Z. Wang, C. Y. Tai, and D. B. Mendel, "Mechanism by which mutations at His 274 alter sensitivity of influenza A virus N1 neuraminidase to oseltamivir carboxylate and zanamivir," Antimicrobial Agents \& Chemotherapy, vol. 46, no. 12, pp. 3809-3816, 2002.

[28] R. B. Belshe, M. H. Smith, C. B. Hall, R. Betts, and A. J. Hay, "Genetic basis of resistance to rimantidine emerging during treatment of inluenza virus infection," Journal of Virology, vol. 62, no. 5, pp. 1508-1512, 1988.

[29] R. A. Bright, M.-J. Medina, X. Xu et al., "Incidence of adamantane resistance among influenza A (H3N2) viruses isolated worldwide from 1994 to 2005: a cause for concern," The Lancet, vol. 366, no. 9492, pp. 1175-1181, 2005.

[30] K. Pabbaraju, K. C. Y. Ho, S. Wong et al., "Adamantane resistance in circulating human influenza A viruses from Alberta, Canada (1970-2007)," Antiviral Research, vol. 79, no. 2, pp. 81-86, 2008.

[31] M. A. Ciblak, M. Hasoksuz, V. Escuret et al., "Surveillance and oseltamivir resistance of human influenza A virus in Turkey during the 2007-2008 season," Journal of Medical Virology, vol. 81, no. 9, pp. 1645-1651, 2009.

[32] J. Müller, A. Naguleswaran, N. Müller, and A. Hemphill, "Neospora caninum: functional inhibition of protein disulfide isomerase by the broad-spectrum anti-parasitic drug nitazoxanide and other thiazolides," Experimental Parasitology, vol. 118, no. 1, pp. 80-88, 2008.

[33] B. E. Korba, M. Elazar, P. Lui, J.-F. Rossignol, and J. S. Glenn, "Potential for hepatitis C virus resistance to nitazoxanide or tizoxanide," Antimicrobial Agents \& Chemotherapy, vol. 52, no. 11, pp. 4069-4071, 2008. 

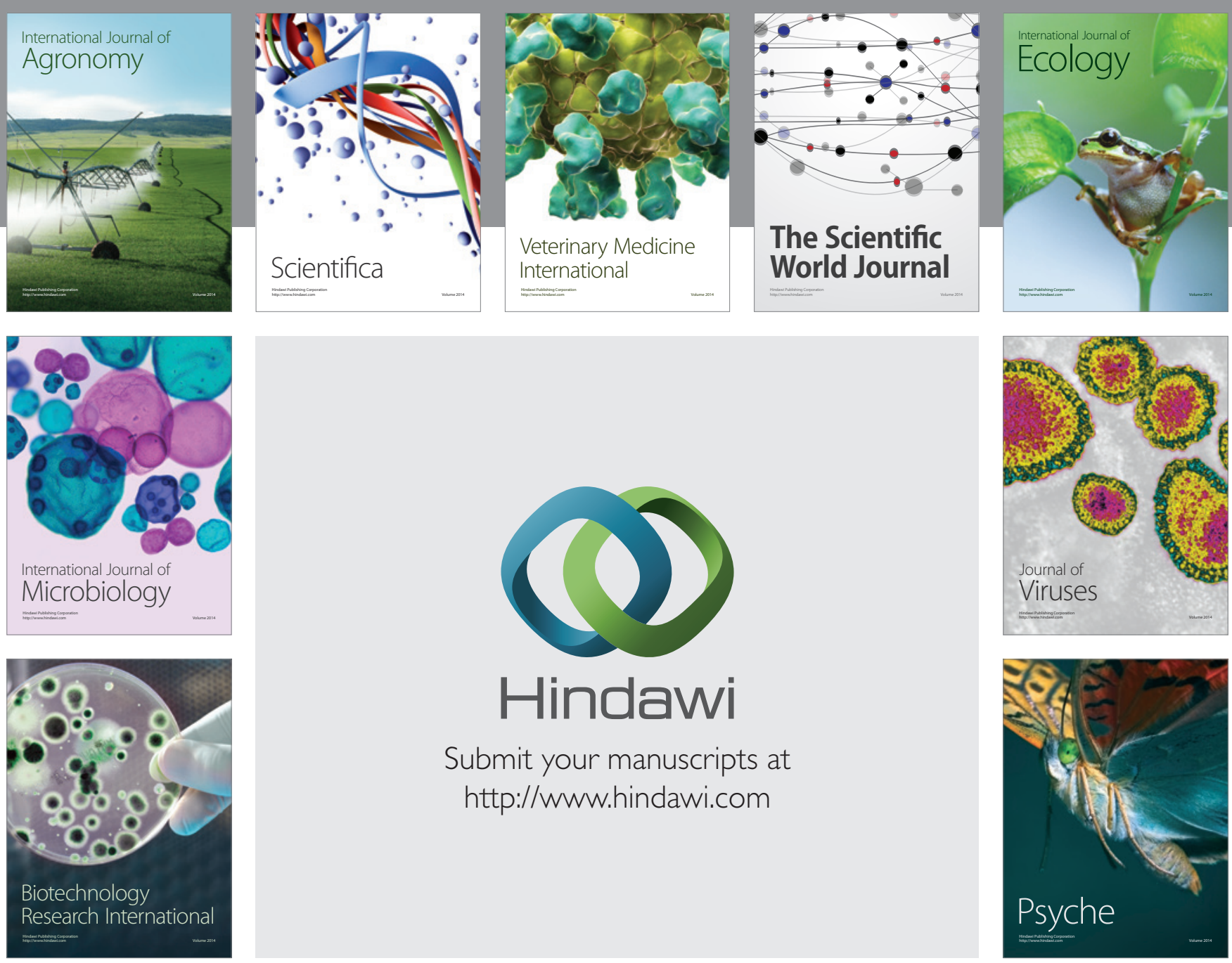

Submit your manuscripts at

http://www.hindawi.com
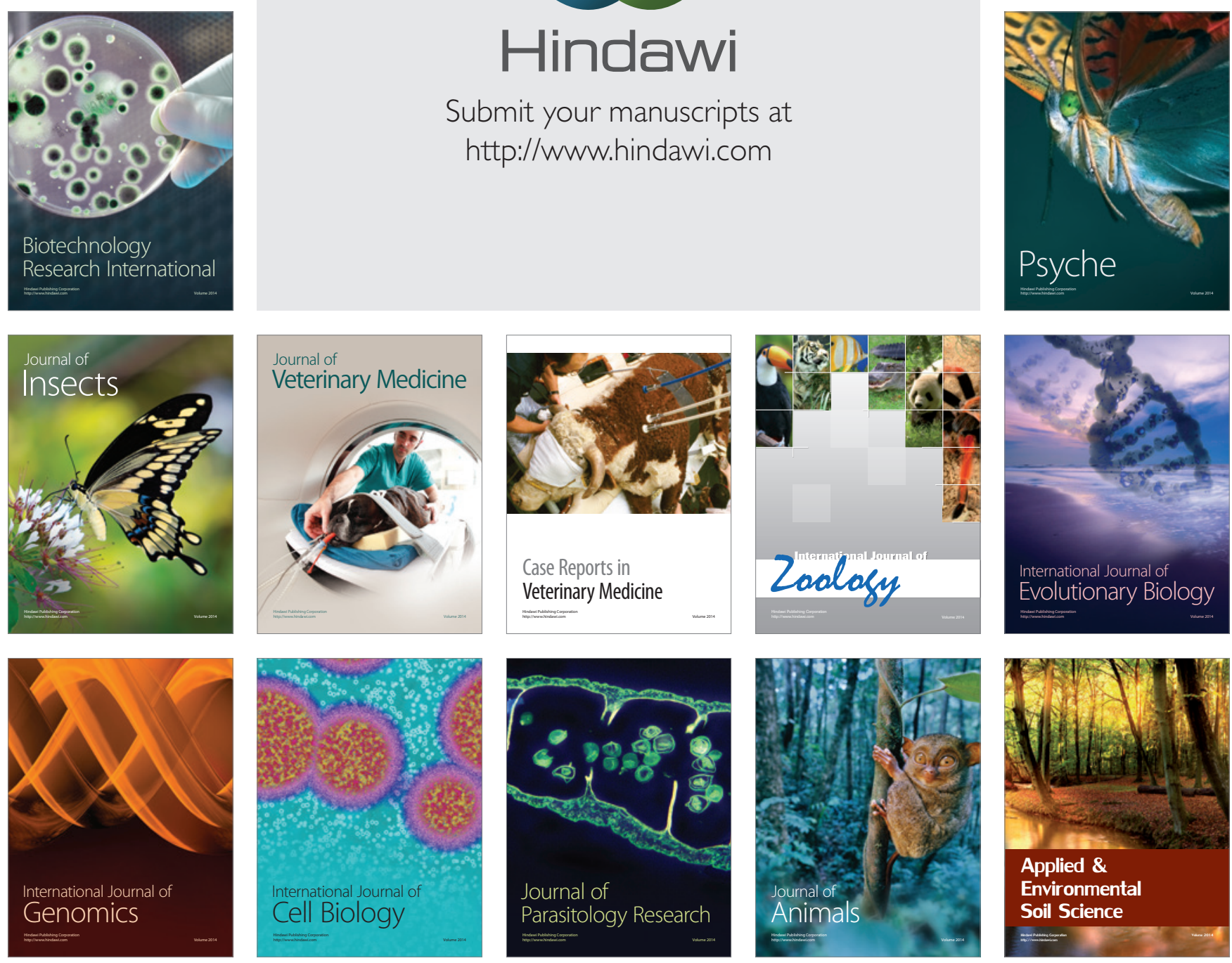